Research Article

\title{
Studies on Preformulation Characteristics and Production of Polymeric Nanoparticles of Sorafenib Tosylate
}

\author{
Jeevana Jyothi B*, Keerthi M, \\ Department of Pharmaceutics, Institute of Pharmaceutical Technology, \\ Sri Padmavati Mahila Visvavidyalayam (Women's University),Tirupati, Andhra Pradesh, INDIA. \\ *Corresponding author's E-mail: jeevanajyothib8@gmail.com
}

Received: 08-01-2021; Revised: 22-02-2021; Accepted: 28-02-2021; Published on: 20-03-2021.

\section{ABSTRACT}

Sorafenib tosylate is a kinase inhibitor approved for both hepatic carcinoma and renal cellular carcinoma. It has drawback of poor solubility and so less cellular uptake. As the nanoparticles are promising to enhance solubility, cellular uptake, the present work aimd at preparation of nanoparticles of Sorafenib tosylate. Preformulation characteristics including interaction studies were carried out. Trial formulations containing different ratios of drug to polymer as 1:1, 1:1.5, 1:2, 1:2.5, 1:3, 1:3.5 were prepared by nanoprecipitation method using pectin as a polymer. Three formulations made with drug to polymer ratio of 1:2.5, 1:3 and 1:3.5.were produced successfully with mean particle size in nano range of $270.8 \mathrm{~nm} 49.1 \mathrm{~nm}$, and $149.3 \mathrm{~nm}$ and respectively.

Keywords: Sorafenib tosylate, hepatocellular carcinoma, pectin, nanoparticles, Nano precipitation method.

QUICK RESPONSE CODE $\rightarrow$

DOI:

10.47583/ijpsrr.2021.v67i01.033

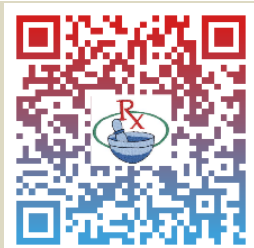

DOI link: http://dx.doi.org/10.47583/ijpsrr.2021.v67i01.033

\section{INTRODUCTION}

G lobal Burden of Disease (GBD) indicates 70 percent of cancer deaths are concentrated among low- and middle-income countries. The prevalence is high in developed nations, but in recent years, it has raised substantially in developing countries as well. ${ }^{1}$ In developing countries, cancers of the liver, stomach, and esophagus are more common and has poor prognosis. Furthermore, as cancer survival data become increasingly available, it is clear that prognosis is much poorer in developing countries, so that the ratio of deaths to cases is much less favorable. ${ }^{2}$

Worldwide cancer is among the leading causes of death. In 2012, there were 14.1 million new cases and 8.2 million cancer-related deaths worldwide. $57 \%$ of new cancer cases in 2012 occurred in less developed regions of the world that include Central America and parts of Africa and Asia; $65 \%$ of cancer deaths also occurred in these regions.

- The number of new cancer cases per year is expected to rise to 23.6 million by 2030 .

The incidence of cancer is rising rapidly in recent decades, which has become a serious threat to human life and health. Most patients have to accept chemotherapy instead of the surgical treatment because the tumor has developed into terminal stage when it is diagnosed. However, the clinical efficacy of chemotherapy is seriously hindered by the subsequent side effects, which has caused increasing attention among experts around the world recently. Nano drug delivery system is a new kind of microparticle sustained release system in nanometer size, which can wrap chemotherapy drugs into carrier materials. ${ }^{3}$

Sorafenib tosylate, one of the most preferred multi-kinase inhibitor drug, has been used as an effective chemotherapeutic for many types of cancer [solid tumors] in liver, thyroid, breast, lung, ovarian etc. However, its use is severely limited by its poor aqueous solubility sideeffects such as loss of appetite, dry skin, mouth sores, hairloss etc. Sorafenib, a potent anticancer drug, has low absorption in the gastrointestinal tract due to its poor aqueous solubility ${ }^{4}$. It was approved by the U.S food and drug administration (FDA) in December 2005 and received European commission marketing authorization in July 2006, both for the use in the treatment of hepatocellular carcinoma in 2007 (a type of liver cancer) that cannot be removed by surgery, Renal cell carcinoma in 2006 (a type of kidney cancer) it is advanced and radio-active iodine resistant thyroid carcinoma. ${ }^{5}$

Sorafenib is a clinically important oral tyrosine kinase inhibitor for the treatment of various cancers. However, the oral bioavailability of sorafenib tablet (Nexavar) is merely $38-49 \%$ relative to the oral solution, due to the low aqueous solubility of sorafenib and its relatively high daily dose. $^{6}$

When many chemotherapeutic agents evidenced poor survival rates, Sorafenib leads to a survival benefit in patients with advanced hepatocellular carcinoma. ${ }^{7}$

Hence the aim of the present research work is studies on preformulation characteristics and production of Sorafenib tosylate as there are very few/no methods are reported in the literature 


\section{MATERIALS AND METHODS}

\section{Materials}

Sorafenib tosylate is a gift sample from Aurobindo Pharma Ltd., Hyderabad. Pluronic F68 and methanol were purchased from Sigma Aldrich Chemicals. Chloroform and DSMO are purchased from Himedia Laboratories. Acetone and Ethanol were purchased from SD fine chemicals Ltd., and Merk Mumbai respectively. Pectin was purchased from Sisco research laboratories Pvt. Ltd., All other chemicals used in the study are of analytical grade.

\section{Methods}

\section{Preformulation studies of sorafenib tosylate}

The documentation of results of preformulation characteristics will acts as ready reference for development of ideal dosage especially for new drugs. As there are no much reported articles on preformulation profile of sorafenib tosylate the present work is carried out on evaluation of various studies such as Solubility, melting point, DSC and FTIR analysis and Drug-excipient interaction studies using, DSC and FTIR analysis .

\section{Solubility studies of sorafenib tosylate}

The solubility of sorafenib tosylate was determined in various solvents such as water, DMSO and acetonitrile, $0.1 \mathrm{~N} \mathrm{HCl}$ to assess its aqueous solubility.

\section{Determination of melting point}

The melting point of the drug was determined by an open capillary tube method. The one end closed capillary tube was taken and the drug was filled into the capillary tube by repeated tappings. Then the capillary tube was placed in the melting point apparatus. The temperature at which the drug started melting was recorded.

\section{Differential scanning calorimetry (DSC) of sorafenib tosylate}

Dry powder samples of the test sample (sorafenib tosylate) weighing 2-5 mg were placed in aluminum pans and were sealed with aluminum caps. Thermograms were taken on a differential scanning calorimeter (Mettler-Toledo, Switzerland) at a heating rate of $10^{\circ} \mathrm{C} / \mathrm{min}$ in nitrogen atmosphere over a temperature range of $200-400^{\circ} \mathrm{C}^{13}$.

\section{FTIR spectroscopy of sorafenib tosylate}

The chemical constituents of the drug were investigated by FTIR Spectroscopy using pressed pellet technique. The FTIR spectrum of the drug was recorded in transmittance mode in the range of $400-4000 \mathrm{~cm}-1$.

\section{Interaction studies between sorafenib tosylate and Pectin}

In the present work polymeric nanoparticles of Sorafenib tosylate were selected to be produced with pectin. Hence compatibility between Sorafenib tosylate and Pectin was assessed by taking FTIR spectra and DSC thermogram for
1: 1 mixture of drug to polymer and investigated for interaction.

\section{Preparation of Sorafenib tosylate loaded nanoparticles} by Nanoprecipitation method

Polymric nanoparticles containing 200mg of Sorafenib tosylate were prepared by solvent displacement method [Fessi, eta]l using pectin as polymeric matrial. Trail formulations with which discrete particles are not obtained is not shown here.Six formulations F1 to F6 containing different ratios of drug to polymer as $1: 1,1: 1.5$, $1: 2,1: 2.5,1: 3,1: 3.5$, were tried and the compositions are shown in Table 1. Accurately weighed $200 \mathrm{mg}$ of sorafenib tosylate was dissolved in a water miscible organic solvent, ethanol. The polymer, pectin (250mg) was dissolved in water. The organic phase was added drop wise to aqueous phase under stirring. Above mixture was added drop wise to $10 \mathrm{ml}$ of dist. water containing non-ionic surfactant $0.5 \% \mathrm{~W} / \mathrm{V}$ pluronic F-68. Then the solution was left for night to evaporate organic solvent. Nanoparticles were then recovered from nano-dispersion by centrifugation for 30 min at $25000 \mathrm{rpm}$, washed two times with distilled water. The dispersion was finally lyophilized for $24 \mathrm{hrs}$ to yield freeze dried nanoparticles. Samples were frozen at $-70^{\circ} \mathrm{C}$ and placed immediately in the freeze-drying chamber.

Table 1: Composition of Nanoparticle formulations F1 to F6 of Sorafenib tosylate

\begin{tabular}{|c|c|c|c|}
\hline $\begin{array}{c}\text { Formulation } \\
\text { (F1-F7) }\end{array}$ & Drug(mg) & Solvent(ml) & $\begin{array}{c}\text { Polymer } \\
\text { Pectin(mg) }\end{array}$ \\
\hline F1 & 200 & Ethanol & 200 \\
\hline F2 & 200 & Ethanol & 250 \\
\hline F3 & 200 & Ethanol & 300 \\
\hline F4 & 200 & $\begin{array}{c}\text { Acetone, } \\
\text { Chloroform }\end{array}$ & 350 \\
\hline F5 & 200 & Ethanol & 400 \\
\hline F6 & 200 & Ethanol & 450 \\
\hline
\end{tabular}

Determination of particle size and zeta potential analysis

The freeze-dried nanoparticles were dispersed in distilled water for particle size analysis using Malvern Zetasizer 3000 (Malvern Instruments, UK). The measurement of nanoparticle size was based on photon correlation spectroscopy. Polydispersity index was studied to determine the narrowness of the particle size distribution. All the measurements were carried out in triplicate.

Zeta potential was studied to determine the surface charge on the nanoparticles using Malvern Zetasizer 3000, (Malvern Instruments, and UK). The zeta potential of the nanoparticles was determined using electrophoretic light scattering. Freeze-dried samples were suspended in distilled water and their zeta potential was determined. All the measurements were carried out in triplicate 


\section{RESULTS AND DISCUSSION}

\section{Preformulation characteristics of sorafenib tosylate}

\section{Solubility studies of sorafenib tosylate}

Solubility studies of sorafenib tosylate shows that it is practically insoluble in water and freely soluble in DMSO, $0.1 \mathrm{NHCl}$, ethanol and acetone. This information is useful in assessment UV method of estimation

\section{Melting point}

The melting point of sorafenib tosylate was found to be $240^{\circ} \mathrm{C}$. This value is in agreement with reported value $(240-$ $243^{\circ} \mathrm{C}$ ) of sorafenib tosylate in literature.

\section{Differential Scanning Calorimetry}

DSC thermogram of sorafenib tosylate is shown in Fig. 1. As revealed in thermogram typical with onset temperature of decomposition was started just above $220.71^{\circ} \mathrm{C}$ and then with endothermic peak was present at $240.29^{\circ} \mathrm{C}$. Melting peak at $237.1^{\circ} \mathrm{C}$. coincides with reported for sorafenib tosylate $\left(240-243^{\circ} \mathrm{C}\right)$ indicating purity of the drug.

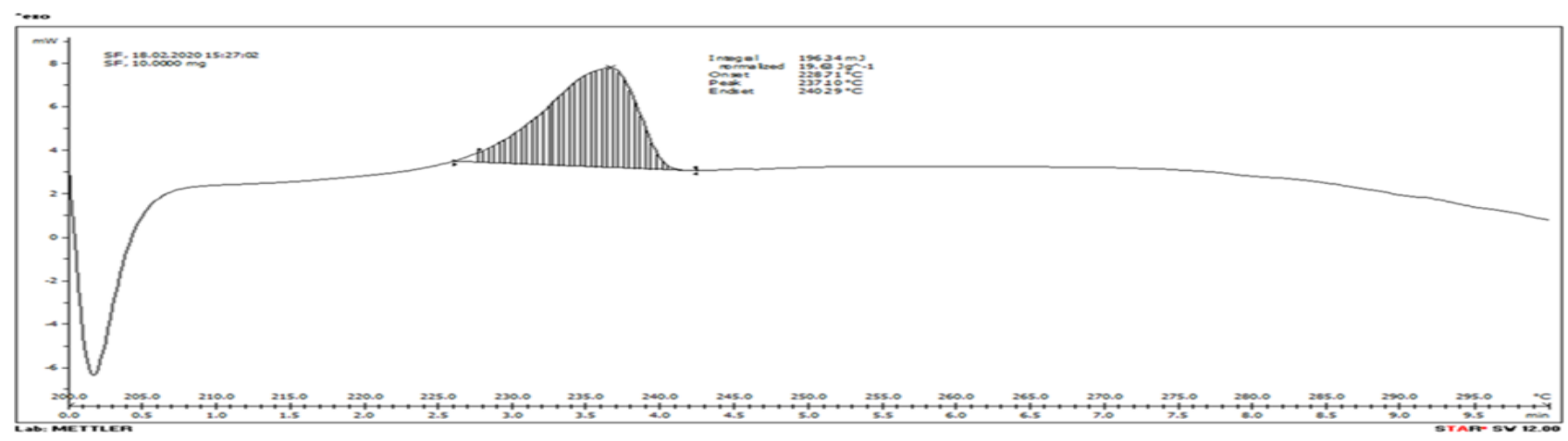

Figure 1: DSC thermogram of sorafenib tosylate

\section{(Fourier transform infrared spectrometry) FTIR spectrum} of sorafenib tosylate

IR spectrum of sorafenib tosylate obtained from FTIR analysis is shown in Fig. 2. Its characteristics peaks are also shown in Table 2. The bending stretch due to $-\mathrm{OH}$ is present at $3350.4 \mathrm{~cm}^{-1},-\mathrm{CH} 3$ stretch at $2978 \mathrm{~cm}^{-1}, \mathrm{C}-\mathrm{NH}$ stretch at $1644.45 \mathrm{~cm}^{-1}, \mathrm{C}=\mathrm{O}$ stretch at 1749.94 and $\mathrm{C}-\mathrm{O}$ stretch at $1102.02 \mathrm{~cm}^{-1}$.
Table 2: FTIR characteristic peak of sorafenib tosylate

\begin{tabular}{|c|c|c|}
\hline S.no & Functional group & $\begin{array}{c}\text { Wavelength } \mathbf{c m}^{-} \\
\text {(obtained) }\end{array}$ \\
\hline 1 & OH bending & 3350.4 \\
\hline 2 & CH3 bending & 2978 \\
\hline 3 & C-NH Stretching & 1644.45 \\
\hline 4 & C=O Stretching & 1749.44 \\
\hline 5 & C-OStretching & 1102.02 \\
\hline
\end{tabular}

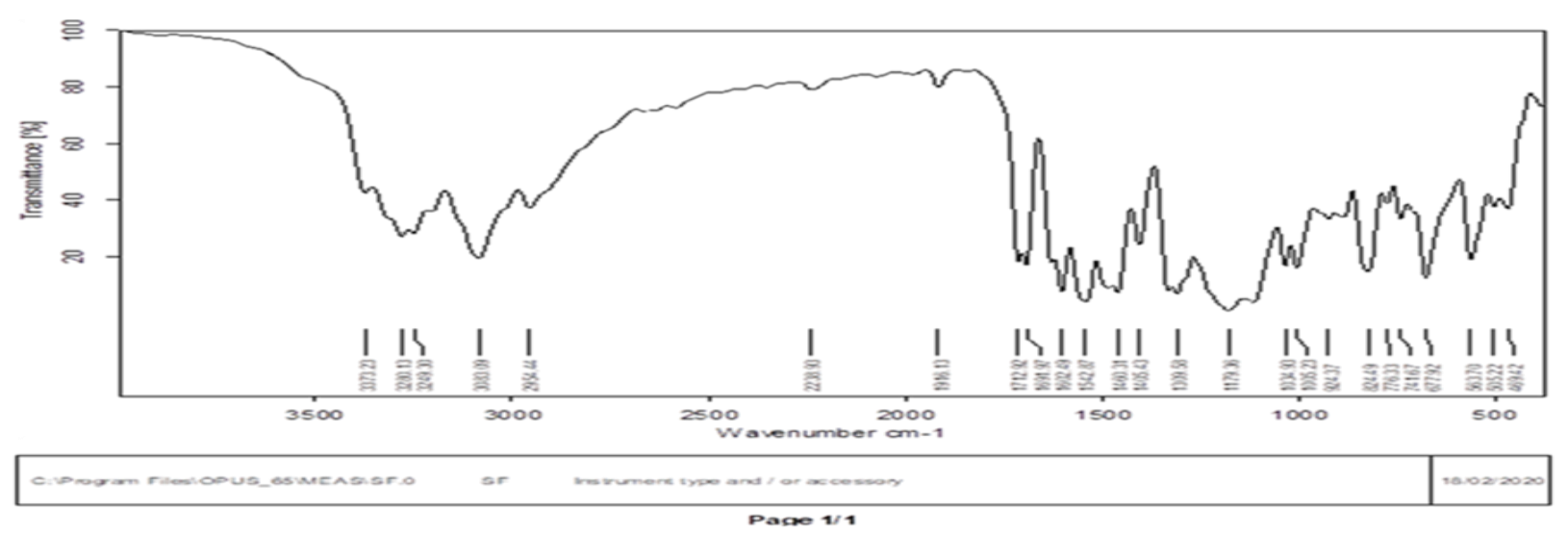

Figure 2: FTIR spectra of sorafenib tosylat

\section{Particle Size and Zeta Potential of Sorafenib tosylate nanoparticles}

Sorafenib tosylate nanoparticle formulations such as F4, F5 and $\mathrm{F} 6$ revealed to be produced with mean particle size of in nano range of $46.1 \mathrm{~nm}, 149.3$ and $270.8 \mathrm{~nm}$ respectively. Corresponding scan images of these three are presented in
Fig.3, 4 and 5 and the data is given in Table 3. These results indicates that, nanoparticles are produced successfully with drug to polymer ratio of 1:2.5, 1:3 1st 1:3.5. and the present method used for preparation of nanoparticles is successful in producing nanoparticles in ideal nano size range. The low PI values in case all three formulations indicated the uniformity of particle size. 
These formulations especially F5 and F6 can be promising therapeutics to cross BBB in treatment of glioma as the particles in the range of $50-200 \mathrm{~nm}$ are effective to cross in treatment of brain tumours ${ }^{8}$.
Table 3: Particle size and zeta potential data of sorafenib tosylate nanoparticles

\begin{tabular}{|c|c|c|}
\hline $\begin{array}{c}\text { Formulation } \\
\text { (F1-F7) }\end{array}$ & $\begin{array}{c}\text { Mean particle } \\
\text { size (nm) }\end{array}$ & PI value \\
\hline F4 & 270.8 & 1.264 \\
\hline F5 & 49.1 & 5.463 \\
\hline F6 & 149.3 & 1.845 \\
\hline
\end{tabular}

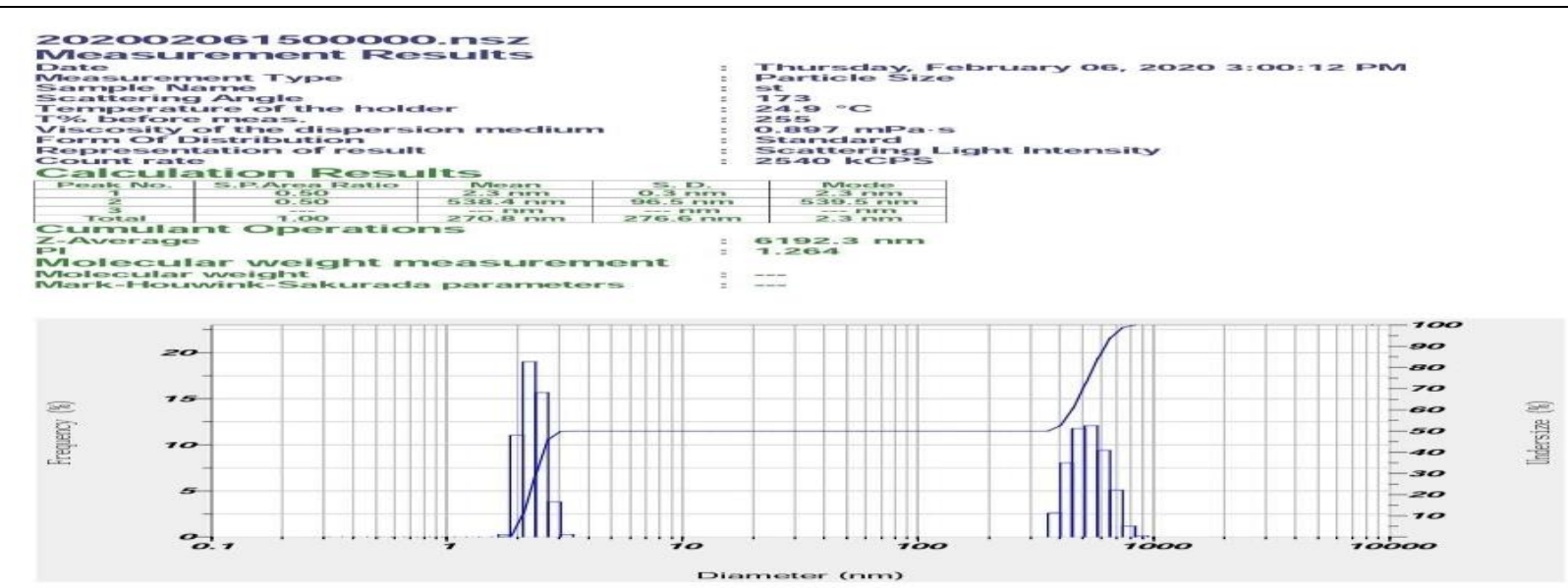

Figure 3: Particle size of sorafenib tosylate nanoparticles F4
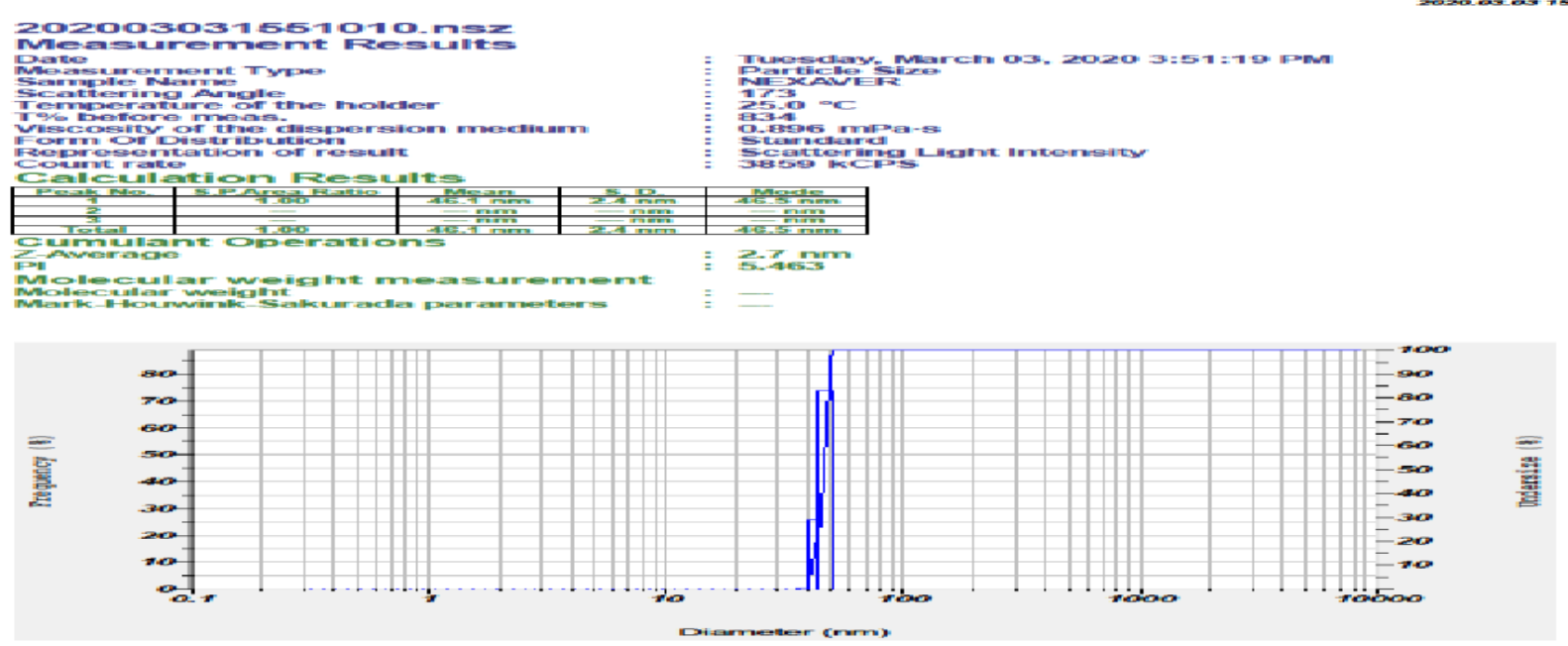

Figure 4: Particle size of sorafenib tosylate nanoparticles F5
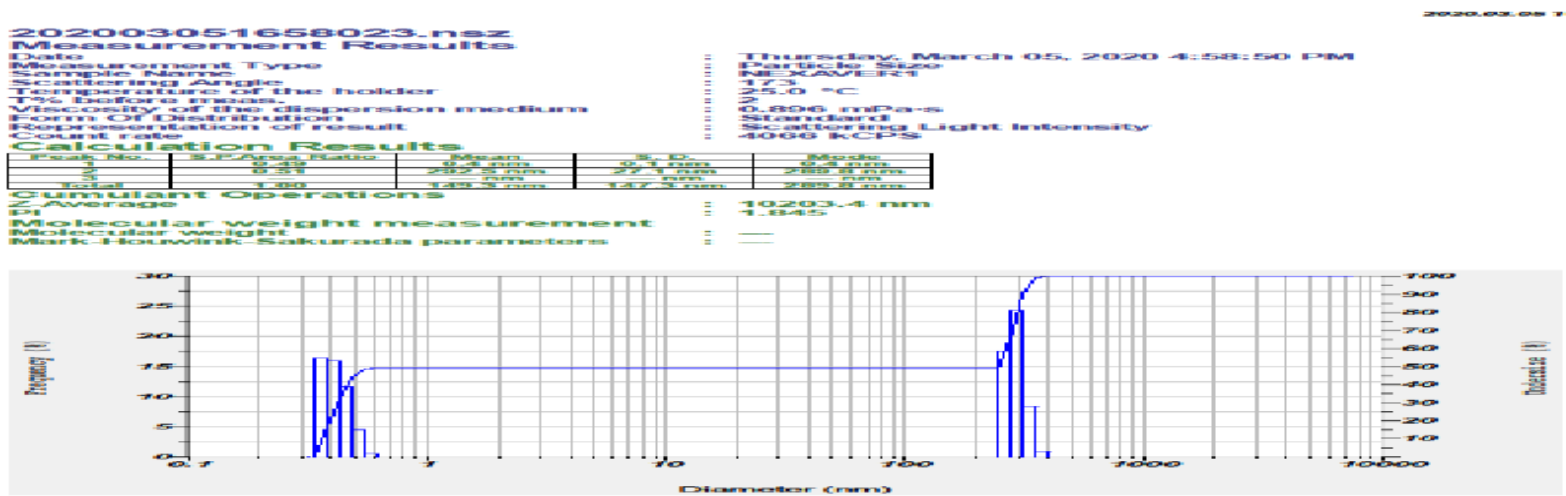

Figure 5: Particle size of sorafenib tosylate nanoparticles F6 


\section{Drug- Excipient Interaction Study in Formulation F3}

To assess any incompatibility between sorafenib tosylate and the excipients used for preparation of pectin nanoparticles, the formulation F3 was analyzed by FTIR and its IR spectrum is shown in Fig.7. For easy comparison the absorption peaks of pure sorafenib tosylate and the nanoparticles of formulation F3 are given in Table 3. It is evident from the results that there is very shift in the characteristic peaks of sorafenib tosylate when it is prepared as nanoparticles. Hence it is concluded that, there is no interaction of drugs with excipients used to prepare nanoparticles.

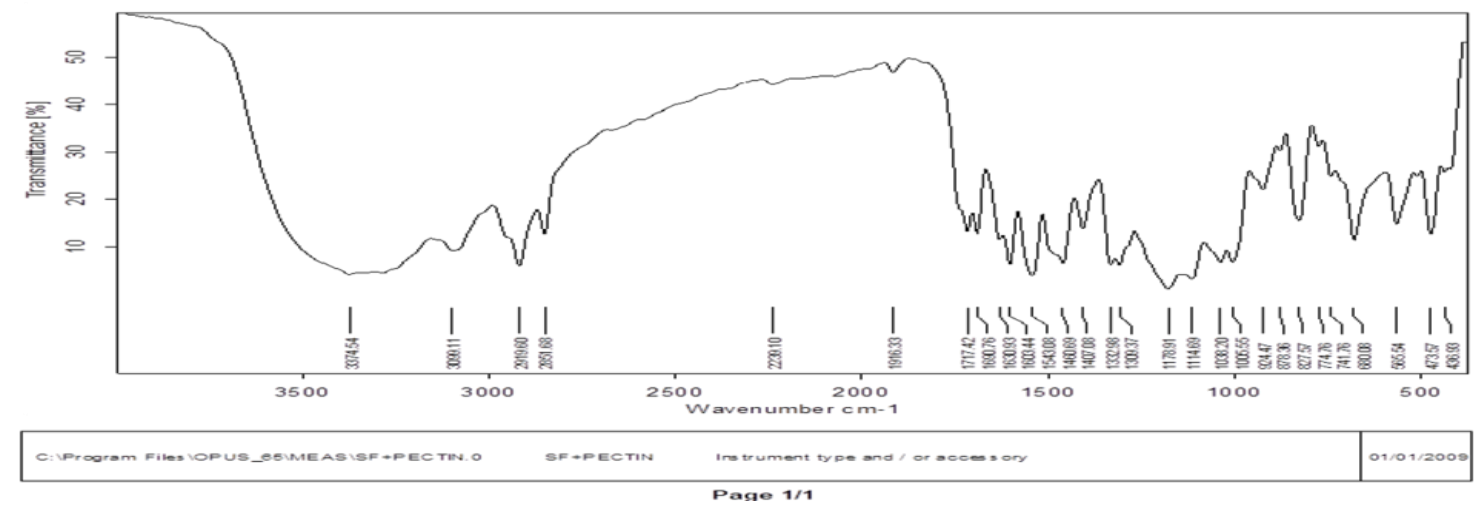

Figure 7: FTIR spectra of sorafenib tosylate and pectin

Table 5: FTIR spectrum values of sorafenib tosylate

\begin{tabular}{|c|c|c|c|}
\hline S.no & Functional group & $\begin{array}{c}\text { Drug } \\
\text { Wavelength } \mathbf{c m} \text { - (obtained) }\end{array}$ & $\begin{array}{c}\text { Pectin } \\
\text { Wavelength } \mathbf{~ c m} \text { - (obtained) }\end{array}$ \\
\hline 1 & OH bending & 3350.4 & 3374.54 \\
\hline 2 & CH3 bending & 2978 & 2919.60 \\
\hline 3 & C-NH Stretching & 1644.45 & 1300.37 \\
\hline 4 & C=O Stretching & 1749.44 & 1717.42 \\
\hline 5 & C-O Stretching & 1102.02 & 1114.69 \\
\hline
\end{tabular}

DSC spectrum of sorafenib tosylate and pectin (Differential Scanning Calorimetry)

DSC, a tool to investigate any physicochemical interaction between the drugs and excipients used for design of formulations. The DSC thermogram obtained in case of sorafenib tosylate shows thermogram peak at $236.47^{\circ} \mathrm{C}$ and the DSC thermogram of formulation F3 in Fig. 8 of the shows sharp endothermic peak of sorafenib tosylate at $229.47^{\circ} \mathrm{C}$ indicating no interaction of drug with excipients used to prepare nanoparticles.

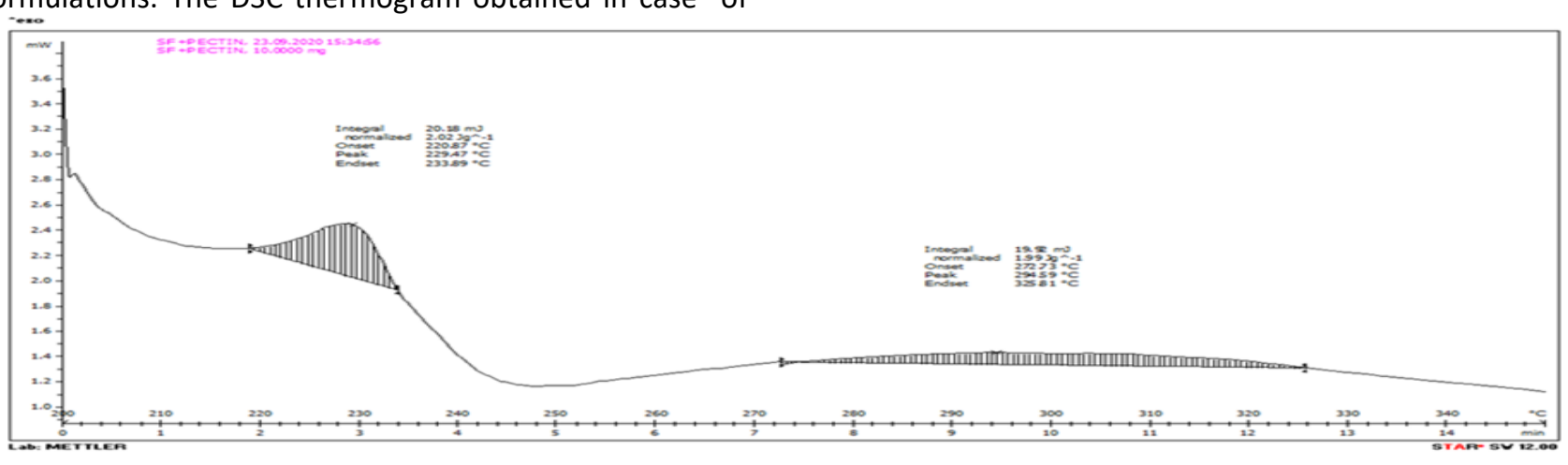

Figure 8: DSC spectrum of sorafenib tosylate and pectin

\section{CONCLUSION}

A novel sorafenib tosylate loaded pectin nanoparticles were successfully prepared by nano precipitation method which can have better cellular uptake to act against tumors. The nanoparticles produced with drug to pectin ratio of $1: 3$ and 1:3.5.are promising with mean particle size in nano range of $49.1 \mathrm{~nm}$ and $149.3 \mathrm{~nm}$.

\section{REFERENCES}

1. Sunil Rajpal, Abhishek Kumar, William Joe; Economic burden of cancer in India; Evidence from cross-sectional nationally representative household survey: PLos One.,2014; Feb26: 2018. 
2. D Max Parkin, Freddie Bray, J Ferlay, Paola Pisani; Global cancer statistics, 2002; CA Cancer J Clin., Mar-Apr 2005; 55(2): 74-108.

3. Nanoparticles; J Pharm Biomed Sci., Published online: 29 May 2016.

4. Yan-jing ZHU, Bo ZHENG, Hong-yang WANG, Lei CHEN; New knowledge of the mechanisms of sorafenib resistance in liver Cancer; Acta Pharmacologica Sinica., 2017; 38: 614-622

5. . WEN Shaohong, OU Jinlai, LUO Rui, LIANG Wenli, OUYANG Ping, ZENG Fen, CHEN Yanwen, XU Zhenxia, ZHAO Wen ${ }^{1}$, LI Sha; Preparation and Release Behavior of Pectin Nanoparticles Loading Doxorubicin; J Pharm Biomed Sci., 2015; 05(05):385-393.

6. Sang YeobPark, ZionKang, Prakash Thap, YongSuk Jin, Joo Won Park, Hye Jung Lim, Jae Young Lee, sa-Won Lee, Min-
Hyo Seo Min-SooKim Seong HoonJeong; Development of sorafenib loaded nanoparticles to improve oral bioavailability using a quality by design approach; International Journal of Pharmaceutics., 20July 2019; Vol.566: 229-238.

7. Hannah van Malenstein, Jeroen Dekervel, Chris Verslype, Eric Van Cutsem, Petra Wind molders, Frederik Nevens, Jos van Pelt; Long-term Exposure to Sorafenib of Liver Cancer Cells Induces Resistance With Epithelial-To-Mesenchymal Transition, Increased Invasion and Risk of Rebound Growth: Cancer Letters., 2013 Feb 1; 329(1): 74-83.

8. Liu, C.; Liu, X.N.; Wang, G.L.; Hei, Y.; Meng, S.; Yang, L.F.; Yuan, L.; Xie, Y. A dual-mediated liposomal drug delivery system targeting the brain: Rational construction, integrity evaluation across the blood-brain barrier, and the transporting mechanism to glioma cells. Int. J. Nanomed. 2017; 12: 2407-2425.

Source of Support: None declared.

Conflict of Interest: None declared.

For any question relates to this article, please reach us at: editor@globalresearchonline.net New manuscripts for publication can be submitted at: submit@globalresearchonline.net and submit_ijpsrr@rediffmail.com 